Published in de Souza e Silva, A. \& Glover-Rijkse, R. (eds.) Hybrid Play : Crossing Boundaries in Game Design, Player Identities and Play Spaces. Routledge Advances in Game Studies. London: Routledge.

ISBN 978-0-367-42778-8. http://dx.doi.org/10.4324/9780367855055-8

\title{
$5 \quad$ The hybrid agency of hybrid play
}

Frans Mäyrä

When we engage in play, we become playing subjects - play changes us. When our style of play changes, it also has consequences on how we change while playing. One of the more notable changes in the hybridization of play in recent decades involves blurring and intermixing the boundary between play involving physical objects and play that is primarily engaged with virtual objects, born out of digital computing and media technologies. This chapter discusses play in this hybrid, boundary condition and focuses particularly on the consequences it has for the playing subject by asking: What are the hybrid characteristics of agency in hybrid play?

The situation of all human agency engaged in play is rather complex. Like philosopher Hans-Georg Gadamer (2004) famously argued, "all playing is being-played" (p. 106). When we become playing beings, we are being redefined and framed by the rules and structures of the game in question-player becomes subjected to the game, and game "plays the player." In mixed reality and hybrid games such as Pokémon GO (a location-based game) or Skylanders (a physical-digital hybrid game), the situation of human subjectivity is even more complex. This relates to the multiple frames and multiple layered dimensions of reality that overlap in a hybrid play situation. The everyday, social roles of persons engaged in hybrid play can potentially conflict with the in-game roles that they hold as participants in the play reality: Think, for example, a college student who is, at the same time, in an everyday social role as a student in a classroom while also being an "assassin" in a pervasive live-action game. Some of these overlaps take place through modern technologies such as Global Positioning System (GPS), the radio navigation system owned by the US government, which define certain novel conditions for location-based hybrid play. Given these conditions, the underlying aim of this chapter is to discuss the constitution of agency of hybrid play by alerting us to the power dynamics involved in human-technological systems. Hybrid play with location-based mobile games is the paramount contemporary example of such developments, but there are also other important forms of play that will be addressed by this discussion, such as play with digitally augmented physical toys or physically augmented digital games.

I discuss agency in hybrid play first through the fundamental hybridity underlying all play situations. Particularly, I consider the role of imagination and the potential of play to mean several things at the same time, when approached from different frames of reference or points of view. After a brief philosophical introduction, I address several historical examples that help to highlight the construction and operation of hybrid play agency in practice. These include the introduction of digital technologies into classical, nondigital forms of play and games, the further hybridization of play in various toy-game hybrids, and 
location-based mobile play. The themes of empowerment and confinement run through this discussion: The effects of hybrid play on player's agency appear in this investigation to be somewhat mixed and ambiguous in the end.

\section{The roots of hybrid play}

The philosophers and theorists of play have long debated how to properly address the fundamental character of play. The pervasive and even somewhat "banal" character of play possibly has made it harder to comprehend the full complexity of play - after all, play is commonly associated with something that children do (and adults do less), and there is plenty of evidence of many animal species also engaging in play behaviors - particularly young mammals play, but there is evidence of play even among nonmammals, such as spiders (Riechert, 1978). The agency of animals who engage in play might appear a relatively simple starting point, but it also might shed light to the agency of hybrid human play. Arguably, as symbol-using, cultural beings, humans are the only species to definitely act and play simultaneously in multiple, hybrid realities. Jean Piaget (1951), for example, strongly argued that early play scholars like Karl Groos (1898) were guilty of "anthropomorphic abuse" by attributing make-believe play to animals. In this line of thinking, only humans would truly be able to maintain two realities imposed on top of each other and derive enjoyment of the subsequent playful hybrid experience. The make-believe activities of higher animals such as dogs play-fighting nevertheless remain as a borderline case here (Piaget, 1951).

Philosophically, the roots of hybrid play are ancient, as arguably all play is fundamentally hybrid play. The basic reality of play has a hybrid dimension, which can be approached, for example, from work done in understanding animal play. The scholars of animal play studies recognize the fundamental difference between play and other behaviors that animals engage in, and they note that all play is something that appears to be spontaneous, rewarding in itself, and marked by some features that set it apart from "normal" (or "serious") behaviors - for example, the play versions of animals' behavioral repertoire are often somehow incomplete, or exaggerated versions of non-playful behaviors; an example might be a dog and deer playing "hunting" without being serious and complete in their "hunting" or "escaping" antics (Bateson \& Martin, 2013). The biological foundations of animals — and humans - appear to include play as an additional dimension into their experience of reality: We all have the capacity to settle into a frame or mindset which includes non-productive and non-serious behaviors that are done just for fun. In this line of thinking, play is a behavior that is intrinsically motivated, rewarding, and appears to have its goal in itself. In terms of its ontology, the basic character of play can be found in it being a compound activity that both differentiates and combines two realities into a single hybrid one: the experience of inhabiting a particular mixture of first the physical and serious reality of purpose-driven activities, and, second, the non-serious and playful reality that tends to dominate while engaged in play activities. It should be noted that ontologically, both of these "realities" are primarily mindsets - modes of behaving and thinking that modify our relationship to both material and immaterial dimensions of existence.

When we step beyond the most elementary forms of play which some animal species evidence, and go into games and play of humans, the play situation complicates further: Human play is not only biologically motivated or determined, but it also has many play-related cultural traditions, norms, and values that are passed from generation to generation, and which are also constantly creatively modified. For example, there are classic forms of outdoor play such as hide-and-seek and tag, which appear rather universal, but also change constantly and are accompanied by the invention of new outdoor games. The economic conditions, organization of work and leisure, and conceptions of what is proper behavior for children and adults also affect the forms that play takes in cultures (Sutton-Smith, 1989; Virtanen, 1972). 
It is important to study what characterizes and defines the cultural agency of human play-and particularly the contemporary forms of playful agency that are emerging in the era of hybrid media and information systems.

\section{Cultural agency of play}

In this hybrid context, even coming up with a clear and precise definition of "culture" might be a bit tricky. Generally speaking, there are at least two major traditions of thought that deal with culture: One is based on association of "arts and culture," and the other is rooted in anthropological traditions of thought. A classic definition in the latter tradition is provided by the pioneering anthropologist Edward Burnett Tylor, who, in his work Primitive Culture (1871), defines culture as "that complex whole which includes knowledge, belief, art, morals, law, custom, and any other capabilities and habits acquired by man as a member of society" (p. 1). This is a very wide understanding of "culture" and underlines the many ways in which the different aspects of culture are deeply integrated into our lives and agency as "cultural beings." It is difficult to think about a human without culture, even while the accounts of "feral children" that are raised by animals and have lived isolated from any human contact seem to provide an interesting test case for developmental psychology and philosophy alike. The limited evidence that these individuals can provide seems to suggest that "humans without culture" appear to grow up as fundamentally disabled compared to our norms of human agency; for example, their inability to learn language and adopt "civilized" behaviors and practices makes them seem both mentally impaired and socially misfit when brought back to human contact and community (Candland, 1995; Newton, 2003). Considering this, all studies of human agency are also studies into cultural agency - a fundamentally hybrid phenomenon, including both biological and genetic, as well as socially transmitted and constructed components. There are also no distinctive criteria that would allow differentiating "culture" from "society," for example. From an anthropological perspective, one can, however, study "cultures" in plural: Adopting this approach, it should, therefore, be possible to study the intersections of societal and cultural changes within the late modernity when it interfaces with pervasive technologies and novel play forms that they allow.

The other tradition of thinking about culture does allow certain qualitative distinctions to be made within cultures themselves. In everyday speech, it is this understanding of culture as "the arts and other manifestations of human intellectual achievement" that is the most commonly used (see, e.g., Oxford English Dictionaries). Among all human practices and behaviors, the cultivation of arts and culture is something distinctive and usually highly valued. The cultural history is recorded and taught to the next generation. There can also be differences in cultural agency in this line of thinking: Someone can be more "cultured" than someone else. This has been discussed by sociologist Pierre Bourdieu in his theory of cultural distinctions. According to Bourdieu (1984), people can cumulate and possess different kinds of "cultural capital" that features in their lives in important ways, as it is the foundation for how knowledgeable or sophisticated they appear in various social contexts. For example, the "game cultural agency" in contemporary societies comes with similar kinds of qualifiers. There is distinctive "game cultural capital" that one can achieve by evolving as a football fan, as a golfer — or as an expert in online role-playing games or a particular video game series with a cult following (Consalvo, 2007). Like with other cultural practices, enculturation into game cultures involves development of certain knowledge and skills: in this case something that is often called "ludic literacy." Cultural critics and scholars of games emphasize that being able to just play and having a "naïve understanding" of games has its limits. At a deeper level, game cultural agency also comes with expectations of historical and critical knowledge and 
"analytical know-how," which enables a subject to provide grounds for her critique of games (Mäyrä, 2008; Zagal, 2010). As games are an evolving cultural form, the criteria for this kind of educated game cultural agency are also constantly changing.

Perhaps the most fundamental dimension of understanding and skills in terms of games and play relates to being able to understand that these are forms of "play culture" from the start. Johan Huizinga, a classic of cultural game scholarship, included in his work Homo Ludens (1938/1955) as a key argument the claim that there is a fundamental "play element" in all cultures. Furthermore, Huizinga saw the effects of the play element as wide-ranging and pervasive; in this perspective, play is something that should be taken into account when discussing diverse cultural phenomena such as art, law, war, and philosophy. Huizinga emphasized how play, while a free activity, is "standing quite consciously outside 'ordinary' life" and that it "proceeds within its own proper boundaries of time and space" (p. 13) — which produces a symbolic and functional demarcation of games and play that has become known in later scholarship as the "magic circle" of play and games. While the magic circle of Huizinga has been repeatedly criticized and, arguably, also often understood too literally (Stenros, 2014), his discussion of "illusion" and "makebelieve" of play has received less attention. However, it is crucial to see how the cultural agency of play relies on certain underlying understanding of fantasy: Play takes place within a layer or dimension of reality that is built on imagination. The object and actions that are taken into play gain their particular meaning precisely due to this "what if" dynamics. A pinecone can be a dragon; a wooden stick can be a magic sword. In the state and mindset of play, multiple realities are simultaneously created and maintained in order to give birth for a new hybrid reality of play. This understanding of cultural hybridity as a consequence of our innate capacity for fantasy and imagination forms the starting point for the following discussion of hybrid games and play.

\section{Power, subversion, and fantasy in play}

The cultural analysis of play has from the early stages paid attention to the interesting relationship play has with power in a society. On the one hand, play can appear as something that the powerless do; it is "mere play," after all, rather than real power over the basic life realities - it is unlikely that play can overturn social hierarchies, redistribute wealth, or effect changes in the fundamental ways in which the society operates, for example. On the other hand, it is in playful versions of such "revolutionary" potentials where pleasure and fascination of play reside, to a certain degree. Like Huizinga, Russian literary scholar Mikhail Bakhtin (1984) studied the cultural roles of humor, play, and playfulness in history, and his discussion of the "carnivalesque" is particularly important for understanding the roots of contemporary hybrid street games, among many other things. Bakhtin refers to the ancient history of folk humor, fantasy, and the grotesque, and suggests that the medieval carnivals are a form of speech and action that is relevant for understanding an important subversive cultural tradition that continues even today. Drawing from the traditions of parody and travesty, the carnival is here seen as a cultural site for experimenting and playing with alternative visions of social reality: The regular order of things was overturned, as the dominant tone was changed to one of comic parody and exaggeration. For a while, the fools were kings, and the kings (and all things sacred) were drawn into foolery. Bakhtin speaks about how a carnival "built a second world and a second life outside officialdom" (p. 6) and says that consideration of this "two-world condition" is crucial for understanding the medieval cultural consciousness and the ensuing culture of the Renaissance. Today, the multi-layered character of "ludic realities" overlapping and mixing with the everyday, more utilitarian social realities holds potential for interacting with 
structurally somewhat similar, carnivalesque phenomena. The agency of hybrid play is the one that is capable of keeping contact with such, multiple and even conflicting spheres of reality.

Many contemporary game genres and play forms display influence from literary traditions or the fine arts. One particularly important cultural influence for hybrid play relates to the tradition of fantasy, or the fantastic, in the arts. This is a wider topic than "fantasy games"; yet, it is true that the milieu and game characters in many adventure and role-playing games in particular are drawn from fantastic fiction with dragons, elves, and magic. The deeper, underlying connection with the fantastic concerns the ways in which the agency of game play includes the repertoire of detecting and communicating something as play. Named as "metacommunication" by Gregory Bateson (2000), the play actions carry with them signs that signal: "These actions which we now engage do not denote what those actions for which they stand would denote" (p. 180). The play actions as carried out by a hybrid, playful agent are always also parts of a fantasy reality, where an attack, or struggle, for example, becomes an enjoyable and exciting experience, rather than threatening one.

Ample use of imagination, and particularly mixing it with the everyday social reality, comes with its own potential conflicts and ambiguities. Even the linguistic and etymological roots of "fantasy" suggest that it is a loaded concept; on the one hand, "fantasy" (as derived from Greek phan', "to appear or seem") is used to discuss something that is imagined or dreamed - a highly desirable reality. On the other hand, "fantasy" is also used like the "phantasma," to discuss "delusions" and "figments of the imagination"something irrelevant or even dangerous. The fantastic tradition in the arts is popular yet conflicting in its reception and cultural status. The fantastic elements of ancient myths, for example, have been the target of critique and (loving) satire at least since Lucian of Samosata and his second century A.D. satirical fantasy work A True Story ('A $\lambda \eta \theta \tilde{\eta} \delta \eta \eta \eta \dot{\mu} \mu \alpha \tau \alpha$ ). Literary scholar Rosemary Jackson (1981) writes about fantasy as "the literature of subversion" and notes that while it is the cultural role of fantasy to provide opportunities for exploring "taboo" topics and evoking the (often subconscious) conflicts that underlie our socially and culturally constructed "selves," fantasy often frequently serves (as in the case of Gothic fiction) to reconfirm institutional order of things. The fantasy can work as a temporary escape from this shared normative reality by supplying "vicarious fulfilment of desire" and "neutralizing an urge towards transgression" in the end (Jackson, 1981, p. 41).

The dynamics of contemporary hybrid games come embedded within similar, culturally ambiguous power dynamics. It is indeed typical for play and games to provide incentive for the creation of "alternative orders" and operational logistics. This is a dimension that has been raised into headlines by the proponents of "gamification" in particular. For example, Jane McGonigal (2011) has argued that our current social reality is "broken" (dysfunctional and unsatisfactory) and, if lessons of good game design would be applied in the context of real-life problems rather than just ludic fantasy, there could be immense potential for societal and individual transformation through game play. There are indeed ongoing efforts to design services and experiences that would be as engaging as good games, while also providing multiple benefits in addition to enjoyment derived from the fantasy dimensions of games. The most popular hybrid games of today nevertheless continue to prioritize the engaging and enjoyable character of imaginative play realities over the real-life goals or consequences.

\section{Physical and digital in hybrid play}

The engaging and enjoyable character of hybrid play is interesting in itself. As noted earlier in this chapter, all play is hybrid by character, and the cultural character of ludic agency is fundamentally rooted 
in our ability to combine and negotiate between multiple dimensions of constructed reality, some playful, some less so. But it is with the rise of digital, computer, and video games where the concept of hybrid games and play started to gain broader relevance. The veritable Renaissance of game design and new ways of playing that followed the early experiments and the first generations of video games meant that there were suddenly both new kinds of implementations of traditional games and completely new kinds of experiences available that were made possible by the advances in computing and digital audiovisual technologies. In 1952, it was possible for the first time to play tic-tac-toe, a simple paper-and-pencil game on a computer terminal $(O X O)$, then in 1958 to play simplified tennis (Tennis for Two) on an oscilloscope screen, and in 1962 a computer game designed to simulate fighting spaceships (Spacewar!) was released to a select audience of early mainframe computer users. In all these cases, the experience of traditional games was fundamentally altered by the technical requirements of computing hardware: There was no physical paper used by the tic-tac-toe players, nor physical rackets in the electronic tennis version (Kent, 2001). In the case of Spacewar!, there were no direct predecessors among traditional games (as autonomously moving playing pieces were not part of classical games), and it should also be noted that the closest earlier game forms such as miniature wargames differ fundamentally in their tactile nature.

It is in the nature of physical toys to naturally support and encourage hybrid play: the mapping of imaginative characteristics or fantasy reality with associated playful functionalities on physical objects (Heljakka, 2019). For a long time, computer and video games developed into an opposite direction. The digital game player needed to internalize the button-presses, typed keyboard commands, or other arbitrary operations that the computerized user interface required. During the early decades of computer and video games, there were few attempts at bridging the digital and physical realities in a more intuitive manner, for example by developing games that used plastic "light guns" for shooting at targets in the monitor display. Such combinations of physical and digital play started to expand in two ways, starting in the 1980 s and entering mainstream in the early 2000s. First, the handheld video gaming devices, such as Nintendo's Game \& Watch series (from 1980 onward, followed eventually by the first Game Boy device in 1989) started to feature digital game play that was also increasingly connected with mobile experiences. In 1997, the first known mobile phone game — Snake by Nokia — appeared preinstalled in mobile handsets (Mäyrä, 2015). Second, the introduction of multiple different sensor types (such as accelerometer, gyroscope, heart rate, and touchscreen sensors) allowed techniques for implementing game play that tied the physical reality more intimately with the digital dimensions. In the area of video game consoles, Nintendo was again in the forefront. In 2006, the Nintendo Wii console was released, including a new type of game control, the Wii Remote. This control device was designed to track the natural motions of players' hands with the help of an accelerometer and optical sensor. With this technology, it was possible, for example, to play tennis in a virtual tennis court by physically simulating the hand movements and the trajectory needed to make a successful serve in a real-life tennis game. The virtual, ingame agency that is represented by the player's avatar on-screen is in this case (more or less accurately) reflecting the embodied agency of the playing subject. In reality, many players soon noticed that it was relatively easy to "fool" the system, if so desired, and play the games with very minimal physical movements, while sitting on a sofa. The in-game realities thus still remained fundamentally disconnected from the embodied and physical realities of the players, even while the hybridization involved increasingly close, parallel developments in physical and digital, simulated or virtual domains.

The potential for combining physical and digital in novel, hybrid experiences has continued to evolve, particularly as it has become easier to embed tiny sensors in all kinds of physical objects, implement touch-sensitivity into multiple objects and surfaces, link embedded microphones and voice commands to programmed functionalities, use light-sensors and cameras to make objects react to proximity, and implement types of pattern recognition. When such technological developments are combined with low- 
power wireless connectivity, the option for implementing a sort of "Internet of Playful Things" starts to open up. The conventional industry-driven vision of "Internet of Things" (IoT) is focused on implementing home automation, remote monitoring, or health solutions with wearable technology (Ometov et al., 2017). But the same basic technologies are open for exploitation into games, toys, and playful designs of other sorts.

\section{Studies of hybrid play: toys and games}

At Tampere University, our research group in the Game Research Lab has studied hybrid play forms and game experiences from the early 2000s, and this work has been informed by the technological changes outlined earlier. We have noted the increasing hybridization of such, previously relatively distinct play and game types as gambling and gaming, mobile phone play and video game play, social media usage, and online gaming (Mäyrä et al., 2017). A series of studies on such emerging fields led into a two-year research project to study the hybridization of physical and digital playthings ("Hybridex," 2012-2014). Under such closer analysis, the blurring and hybridization of play appeared as a wide-ranging and quickly evolving phenomenon. We could detect how the game industry and toy manufacturing were intermixing with franchises such as Activision's Skylanders (2011-) product line, which was followed by other toyaugmented videogame products, the Disney Infinity (2013-) series and Nintendo's Amiibo toys (2014-). The popular construction toy company, LEGO, also introduced its own hybrid toy-game product line, Lego Dimensions, in 2015. These products provide the players with diverse experiences, including collecting and controlling experiences that are derived from tangible toys, set within the context of digital, video game play. The crossing of boundary lines between physical toy and digital game is typically implemented with the use of sensors: e.g., in a Skylanders game, there is an RFID chip embedded into a toy-game figure, which is then used to access the in-game digital version of same character when placed on the provided "Portal of Power"- which is technically just an RFID reader that communicates between the physical toy and the digital game world. When the hybrid experiences in this wide, emerging category are analyzed, certain design patterns can be detected, e.g., implementation of hybrid play by synchronizing or asynchronizing the physical and digital dimension of play; or by making the physical or digital play dimension either dependent or independent of the other play dimension; or by implementing "open play" or "closed play" in a complementary manner in the physical and digital game-toy dimensions (Tyni et al., 2016).

From the perspective of hybrid play agency, the augmentation of digital game designs with tangible toys and other physical additions may appear like an empowering direction of development. After all, while some digital games are open for creative inputs from players- e.g., the open world, "sandbox" style games, and games that support "modding" or sharing user-created content—in many cases the game design imposes a certain actionable script on the player.

The toy designs can be empowering or limiting in terms of player agency. The LEGO construction toys are one interesting example of this. The central idea of plastic bricks is focused on open-ended construction play and the creation of playful, self-created designs as play. This idea was changed in the late 1990s, when LEGO Company reacted to the increasing mediatization and technologization of children's (and indeed almost everyone's) experiential reality by starting to introduce tie-in products such as Star Wars themed LEGO sets (Hjarvard, 2004). The new sets also came with more "preformed" parts, rather than just the basic brick shapes. Like Maaike Lauwaert (2009) writes, this had the consequence of inviting media-inspired play with LEGOs, but also of decreasing the play options: Once constructed according to the provided instructions, the new LEGO pieces were no longer as open for completely new, 
open designs as the older LEGO pieces with the basic designs were. Marsha Kinder (1993) has discussed the wider implications of this changing toy and media landscape for the play agency. She argues that the popular transmedia franchises are designed to position the children in ambiguous state of "consumerist interactivity"; they are both empowered and limited by the dual form of spectatorship, where they are both invited to passively watch the television series or movies and then to act out the preformed scripts with the tie-in toys, video games, and action figures.

\section{The blending of play: location-based gaming}

Location-based games are another example where the emerging hybrid play agency is becoming realized in ambiguous and internally conflicted manners. The classic forms of location-play such as organizing outdoors treasure hunts go back a long time in history. For instance, the "letterboxing" hobby was popular as early as the 1850s. In the Dartmoor moors in England, people would initially amuse other hikers by placing boxes with a letter or postcard hidden inside. Since then, the number of practitioners in this kind of (adult) outdoor play has grown, and it is typical to make an imprint of the stamp found in a letterbox in one's personal notebook, as a proof of having found the box. The interest in letterboxing might stem from the diverse forms of playful activities that it brings together: outdoor exercise, orienteering, puzzle solving, and forms of arts and crafts. The hobby of geocaching is another modern variant where the digital technologies bring along a particular added hybrid dimension into the experience and practices of play. Geocaching is based on playful appropriation of GPS. GPS was originally developed for military uses by the U.S. Department of Defense in 1973; however, civilian uses were allowed in 1980s, albeit with degraded GPS signals - for "national security reasons." This practice was discontinued in May 2000, after which it became possible to play games that rely on precise positioning with the help of GPS (GPS.org, 2018). It is nevertheless an illustrative example of the ways in which power relations operate: The underlying systemic power is often unequally distributed between different actors in hybrid play.

A technology-centric perspective into hybrid play is to a certain degree valuable in highlighting the historical change and development in the field; yet, as such, it remains insufficient in the end. An alternative is provided by Ville Kankainen et al. (2017) in their definition of hybrid games that relies on conceptual blending theory. Rather than being defined by the "hybridizing capabilities" of some novel technology, hybrid games emerge as a novel ludic category only when they bring together and combine two previously unconnected conceptual domains in a new way; these might be previously non-connected domains of art and entertainment, as in combination of playing music with playing instruments and playing arcade video games, as in case of Guitar Hero and Rock Band style of rhythm video games that feature instrument-shaped gaming peripherals. The source domains can, however, be even further apart from each other in how our everyday concepts and experiences are organized. The ensuing "conceptual blending" thus opens up a new cognitive (and cultural) category, which expands the operative range of play agency. From this perspective, when analyzing hybrid play in digital games, it is not particularly useful to focus only on the use of physical controllers or special peripherals. Every game is in any case embedded within a material reality, so if the game experience does not gain a particularly added conceptual dimension from the mixing of previously disconnected conceptual and experiential domains, the game play experience itself is not particularly "hybrid." The examples that Kankainen et al. (2017) discuss include XCOM: The Board Game (2012) — a game that carries the tagline "You are humanity's last hope" and which sets players fighting against imminent alien invasion. In this game, players use both a selection of physical objects (play tokens, cards, a gaming board) and a smartphone app, which is used to control in-game time, resources, and some game events. XCOM demonstrates how the functionalities, 
experiences, and conceptual mindsets involved in playing video games and board games can be blended to produce a novel type of hybrid board game play. Similarly, the Skylanders series of games relies on the hybrid blending of toy play and video game play, where both toys and games are involved in and intermingled into a new kind of hybrid: The player alternates from manipulating the physical character miniatures to manipulating their animated and interactive digital counterparts - and the ensuing playful blend includes both of these dimensions (Figure 5.1). From the perspective of hybrid play agency, it is important to note that such conceptual blends also involve blending of functionalities: In a physical Skylander toy, there are also "hidden," digital functionalities that become playable in the context of compatible video game; such key functions that are not immediately visible from just looking at the toy figure are activating virtual version of toy character and saving the digital game state inside the physical toy. Hybrid player agency is empowered and expected to engage in play behaviors that relate to multiple dimensions of hybrid games, or their play realities, simultaneously.

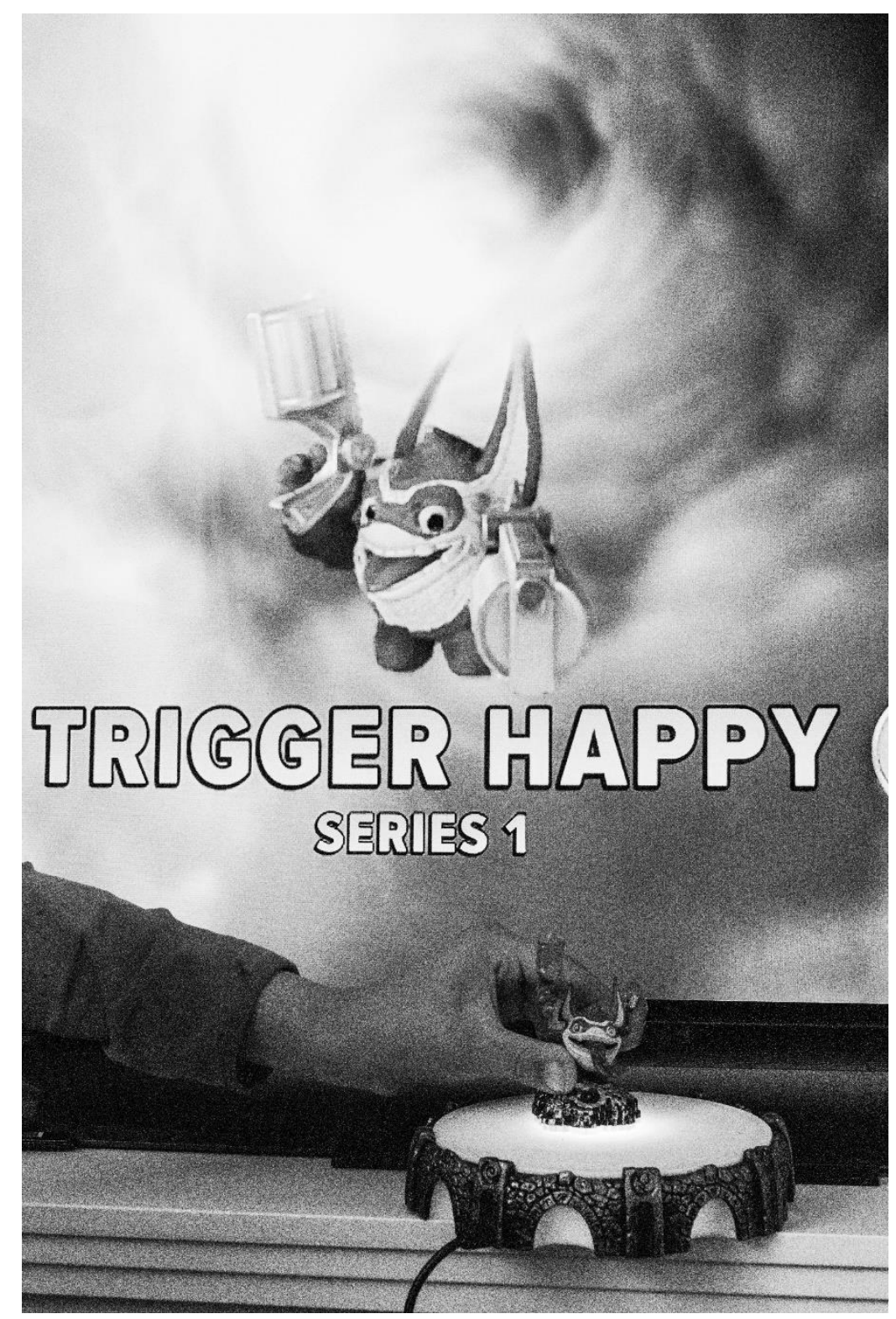


Figure 5.1 Skylanders: a physical toy figure activates the corresponding digital game character. Copyright: Frans Mäyrä.

Coming back to the example of location-based play and games, the agency of traditional treasure hunt style of game is enabled and confined within the playful appropriation of physical spaces. As such, the traditional outdoor player is subject to the laws and norms that govern the use of public and private spaces in a local area. The fantasy of hiding and locating treasures in surprising locations can motivate the players, but there are laws or norms that stop hiding such play treasures inside a grave or into a church, for example, or for setting up a treasure hunt inside a supermarket without permission. The negotiations about the use of space for physical play are embedded in power relations that are economic, political, and also ideological by nature. For example, the inquisitive adventures of the so-called "urban explorers" (urbex) appropriate urban wastelands such as ruined buildings into playgrounds. Doing that, the urbex practitioners (or players) may frequently step into contested areas in the use of abandoned or overlooked spaces that might be off limits or out-of-bounds for the general public. However, like Carrie Mott and Susan M. Roberts (2014) have noted, this re-appropriating and potentially radical practice of "urbex" is embedded within ideological power structures; the agency of urban exploration is often rather masculinist (rich with the rhetoric of "penetration"), and the social privileges and entitlements characterizing the body of urban explorer have so far been largely ignored (p. 10).

When a dimension of digital play is added to location-based activities, additional dimensions also emerge for design and playful exploration. As we argued in an earlier study (Mäyrä \& Lankoski, 2009), the experiential and cultural potential of mixed reality in location-based gaming is inherently liberating and enriching for the playful subjects, and even for the community. There are innumerable novel perspectives and opportunities for meaning-making that open up when "non-tangible" information is made accessible and shared in real-world, physical locations, and played within social settings. Based on our early 20032004 experiments with location-based mobile multiplayer gaming, culminating in The Songs of North (a shamanistic-themed mobile location-based multiplayer game implemented as part of the MOGAME project), we argued that these new forms of hybrid play have the potential to bring games and play back to public spaces, from the confines of private homes where digital gaming has been isolated, at least to a certain degree. Furthermore, the hybrid play holds potential for providing playful incentive and better sense of control for using and creating connections between the domains of digital information systems and everyday environments (Mäyrä \& Lankoski, 2009, pp. 141-145). A recent study (Koskinen et al., 2019) about the memorable and meaningful experiences that players have had while playing Pokémon $G O$ (2016) suggests that these potentials have started to become realized: In addition to interacting with engaging fantasy gaming content, it was the interactions with other people and social experiences in shared spaces that provided the largest numbers of memorable experiences. The hybrid play provided additional incentive and empowerment for talking with strangers in the streets or for coming up with new ways to interact with familiar environments.

Yet, the hybrid play agency in games such as Pokémon $G O$ is framed by tensions and power relations that include most of the ones that were already discussed in the context of physical location-based play (like treasure hunting or urban exploration), but with additional limitations of its own. Playing hybrid games in sparsely populated urban or suburban areas does not come with equal opportunities for males and females, or for minors and adults. There are also important asymmetries in power when the technical and creative aspects of hybrid play agency are discussed. The costs of location services and online access can be prohibitive for some, depending on the mobile phone plans they are able to access. The unlimited mobile data plans are not yet the standard, nor affordable option in many places. The urban emphasis in 
this style of hybrid play is also a limitation for many. Living in a sparsely populated country with little cultural landmarks or tourist attractions that are far apart has consequences for what is being registered into the in-game location database of Niantic (company which created Pokémon GO and its predecessor, Ingress). Typical game play of Pokémon GO, for example, revolves around "Pokéstops" and "Gyms" that are key in-game locations for collecting game resources or for engaging in player-vs-player sessions. And those key game spots are anchored in real-life urban landmarks and attractions. The solitary players, particularly in the countryside, have for a long time been missing out. Something that could help them to have meaningful play experiences would be to give them the power to propose their local points of interest, vantage points, nature trails, or hiking landmarks as in-game landmarks (Pokéstops or Gyms) from within the game. As of this writing (in Summer 2019), there is not yet an in-game system for submitting Pokéstop locations - except for level 40 players in a few specific countries - nor (most importantly) for a solid review process to guarantee fair distribution of such key locations. Future versions of location-based games will indeed need to open up more opportunities for user-created content for truly global reach and equal opportunities in hybrid play to become reality. The fundamental imbalance in hybrid play relates particularly to the limitations that these games impose on creative play agency. While a physical treasure hunt is relatively easy to set up in almost any area (taking into account factors such as the behavioral norms, safety concerns, and the ability to find other co-located players), the programmed digital dimensions in hybrid play still remain rather inflexible. Modifications and "house rules" that are typical for many forms of adaptive, traditional games are a problem for massively multiplayer digital games that are designed with the eye toward large player populations and related concerns of "cheating." The hesitation of Niantic to open up Pokémon GO for their millions of players to submit places to be nominated as Pokéstop or Gym sites might be explained by the unfair advantages such openness might provide for some: Some players might possibly get their school, home, or work places registered as such key sites of the game, leading to tilted in-game resource distribution. An opposite, altruistic example is the player-created practice of city-based Pokémon Go players "adopting" rural players by trading them rare Pokémon as gifts (Stefansky, 2019).

It must be remembered that while hybrid play is a complex phenomenon, it can be in various ways empowering. Yet, it also has built-in potentials for power imbalance and abuse. Regardless of the type of technology employed, there will also always be cultural, behavioral, and community-related conflicts and challenges that any hybrid game needs to overcome. For example, finding like-minded people who share compatible ideas of what are interesting, fair, and fun ways to play together remains as a human challenge that new technologies can solve only to limited degree.

\section{Conclusion: power and ambiguity of hybrid play}

In the end, on the basis of aforementioned discussion, we can conclude that there are at least two sorts of consequences from the blending of digital and physical dimensions in contemporary hybrid play. First, these games and play forms act as a valuable reminder about the fundamental hybridity concealed in all play: The digital and virtual elements of modern toy-game hybrids or location-based mobile games make more visible how all play is rooted in negotiating and intermingling of multiple realities - some material, some immaterial. The hybrid play agency from this perspective is the one that is creative and empowered: The hybrid play enables access and blending of fantasy with reality with even potentially transgressive consequences. Second, the contemporary hybrid game and play forms are also tied with technology in a manner that confines the hybrid play agency. The asymmetric power relations that are not exclusive to but aggravated in technologically augmented play forms limit the players' ability to create their own game 
content, or to design own "house rules" for play, and they steer players into pre-scripted and commercially motivated narratives and behaviors. In this sense, the empowerment of contemporary hybrid play agency is the one that is also subjected to multiple framings: technological, economic, and ideological. Hans-Georg Gadamer's (2004) claim that all playing is also "being played" (p. 106) is consequently particularly true in the case of hybrid games and play: The players of hybrid games are simultaneously embedded within multiple frames of reference that have both empowering and confining consequences for their agency. All this contributes in different ways to their fascinating characteristics and to their significance as subjects of study.

\section{References}

Bakhtin, M. M. (1984). Rabelais and His World. Bloomington: Indiana University Press.

Bateson, G. (2000). Steps to an Ecology of Mind: Collected Essays in Anthropology, Psychiatry, Evolution, and Epistemology. Chicago: University of Chicago Press.

Bateson, P. \& Martin, P. (2013). Play, Playfulness, Creativity and Innovation. Cambridge: Cambridge University Press.

Bourdieu, P. (1984). Distinction: A Social Critique of the Judgement of Taste. Cambridge, MA: Harvard University Press.

Candland, D. K. (1995). Feral Children and Clever Animals: Reflections on Human Nature. Oxford: Oxford University Press.

Consalvo, M. (2007). Cheating: Gaining Advantage in Videogames. Cambridge, MA: The MIT Press.

Gadamer, H.-G. (2004). Truth and Method. London \& New York: Continuum International.

GPS.org (2018). Selective Availability. GPS.Gov (web site). https://www.gps.gov/systems/gps/modernization/sa/.

Groos, K. (1898). The Play of Animals. London: Chapman and Hall.

Heljakka, K. (2019). Toys and Universal Guidelines for Design: A Designerly Perspective on Playability of Character Toys. In: Proceedings of Universal Design 2019. Presented March 5, 2019, Universal Design 2019, Bangkok.

Hjarvard, S. (2004). From Bricks to Bytes: The Mediatization of a Global Toy Industry. In European Culture and the Media, edited by I. Bondebjerg \& P. Golding, 43-63. Bristol: Intellect Books.

Jackson, R. (1981). Fantasy, the Literature of Subversion. London: Methuen. 
Kankainen, V., Arjoranta, J. \& Nummenmaa, T. (2017). Games as Blends: Understanding Hybrid Games. Journal of Virtual Reality and Broadcasting, 14 (4).

Kent, S. L. (2001). The Ultimate History of Video Games: The Story Behind the Craze That Touched Our Lives and Changed the World. New York: Three Rivers Press.

Kinder, M. (1993). Playing with Power in Movies, Television, and Video Games: From Muppet Babies to Teenage Mutant Ninja Turtles. Berkeley: University of California Press.

Koskinen, E., Leorke, D., Alha, K. \& Paavilainen, J. (2019). Player Experiences in Location-Based Games: Memorable Moments with Pokémon GO. In Augmented Reality Games I: Understanding the Pokémon GO Phenomenon, edited by V. Geroimenko, 95-116. Cham: Springer International Publishing.

Lauwaert, M. (2009). The Place of Play: Toys and Digital Cultures. Amsterdam: Amsterdam University Press.

Mäyrä, F. (2008). An Introduction to Game Studies: Games in Culture. London \& New York: Sage Publications.

Mäyrä, F. (2015). Mobile Games. In International Encyclopedia of Digital Communication \& Society, edited by Robin Mansell et al. Hoboken, NJ: Wiley-Blackwell.

Mäyrä, F. \& Lankoski, P. (2009). Play in a Hybrid Reality: Alternative Approaches into Game Design. In Digital Cityscapes: Merging Digital and Urban Playspaces, edited by A. de Souza \& D. Sutko, 129147. New York: Peter Lang.

Mäyrä, F., Stenros, J., Paavilainen, J. \& Kultima, A. (2017). From Social Play to Social Games and Back: The Emergence and Development of Social Network Games. In New Perspectives on the Social Aspects of Digital Gaming: Multiplayer 2, edited by R. Kowert \& T. Quandt, 11-31. New York: Routledge.

McGonigal, J. (2011). Reality Is Broken: Why Games Make Us Better and How They Can Change the World. New York: Penguin Press.

Mott, C. \& Roberts, S. M. (2014). Not Everyone Has (the) Balls: Urban Exploration and the Persistence of Masculinist Geography. Antipode, 46 (1): 229-245.

Newton, M. (2003). Savage Girls and Wild Boys: A History of Feral Children. London: Faber \& Faber. 
Ometov, A., Bezzateev, S. V., Kannisto, J., Harju, J., Andreev, S. \& Koucheryavy, Y. (2017). Facilitating the Delegation of Use for Private Devices in the Era of the Internet of Wearable Things. IEEE Internet of Things Journal, 4 (4): 843-854.

Piaget, J. (1951). Play, Dreams and Imitation in Childhood. London: Heinemann.

Riechert, S. E. (1978). Games Spiders Play: Behavioral Variability in Territorial Disputes. Behavioral Ecology and Sociobiology, 3 (2): 135-162.

Stefansky, E. (2019). Who's Still Playing Pokémon GO Three Years Later? Thrillist, 22 June 2019. https://www.thrillist.com/entertainment/nation/pokemon-go-who-still-plays-three-years-later.

Stenros, J. (2014). In Defence of a Magic Circle: The Social, Mental and Cultural Boundaries of Play. Transactions of the Digital Games Research Association, 1 (2): 147-185

Sutton-Smith, B. (1989). Children's Folk Games as Customs. Western Folklore, 48 (1), 33-42.

Tylor, E. B. (1871). Primitive Culture: Researches into the Development of Mythology, Philosophy, Religion, Art and Custom. London: John Murray.

Tyni, H., Kultima, A., Nummenmaa, T., Alha, K., Kankainen, V. \& Mäyrä, F. (2016). Hybrid Playful Experiences: Playing between Material and Digital - Hybridex Project, Final Report. Tampere: University of Tampere. http://tampub.uta.fi/handle/10024/98900.

Virtanen, L. (1972). Antti pantti pakana: kouluikäisten nykyperinne. Porvoo \& Helsinki: WSOY. Zagal, J. P. (2010). Ludoliteracy: Defining, Understanding, and Supporting Games Education. 1 edition. Pittsburgh, PA: ETC Press. 